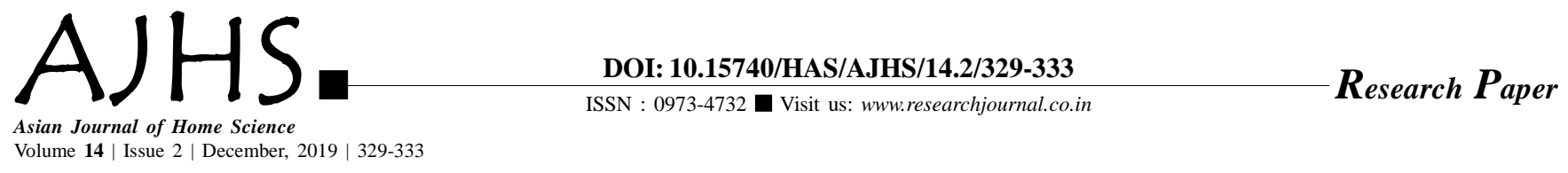

\title{
Inter gender sharing of drudgery by male and female farmers in agricultural activities- an assessment among plain tribe of Lakhimpur district of Assam
}

\author{
G. Konwar, N. Bhattacharyaa, B. Sharma and M. Baruah
}

Received: 20.06.2019; Revised: 14.10.2019; Accepted: 28.10.2019

See end of the paper for authors' affiliations

\section{Baruah}

Department of Family Resource

Management and Consumer

Science, Faculty of Community

Science, Assam Agricultural

University, Jorhat (Assam) India

Email : moontybaruah@gmail.

com
ABSTRACT : Assessment of inter gender sharing of drudgery in performing various agriculture activities by male and female farmers specially in paddy cultivation was carried out among plain tribes of Lakhimpur district of Assam. Multi-stage purposive cum random sampling method was adopted for selecting the representative sample in order to fulfil the objective of the investigation. A total of 120 tribal households from five villages (purposive cum randomly) were selected for the study. As the study focused on inter gender sharing of drudgery in agricultural activities, both male and female farmer were selected for the study. Thus total sample size of the study was 240 numbers comprising 120 male and 120 female farmers. Findings revealed that male farmers spent highest time in transplanting of grain to the home (128.56 mean hr/year) as well as felt very difficult among different activities during paddy cultivation, whereas women spent highest time in cutting crops (179.37 mean hr/year) and majority of women felt very difficult to perform activities like hoeing and uprooting of seedling. Drudgery index in case of male farmers was highest in transportation of grain from the field to home (55.33), followed by hoeing (53.33) and weeding (52.66). In case of female farmers the activity which had high drudgery index was transplanting (56.13) followed by cutting of crops (55.00) and hoeing (53.31).

KEY WORDS: Farmer, Inter gender, Drudgery, Agriculture operation

- HOW TO CITE THIS PAPER : Konwar, G., Bhattacharyaa, N. Sharma, B. and Baruah, M. (2019). Inter gender sharing of drudgery by male and female farmers in agricultural activities- an assessment among plain tribe of Lakhimpur district of Assam. Asian J. Home Sci., 14 (2) : 329-333, DOI: 10.15740/HAS/AJHS/ 14.2/329-333. Copyright@ 2019: Hind Agri-Horticultural Society. 